\title{
Overexpression of the Tibetan Plateau annual wild barley (Hordeum spontaneum) HsCIPKs enhances rice tolerance to heavy metal toxicities and other abiotic stresses
}

Weihuai Pan ${ }^{1,2+}$, Jinqiu Shen ${ }^{3+}$, Zhongzhong Zheng ${ }^{3+}$, Xu Yan $^{1}$, Jianxin Shou ${ }^{2}$, Wenxiang Wang ${ }^{3}$, Lixi Jiang ${ }^{4}$ and Jianwei $\operatorname{Pan}^{1 *}$ (i)

\begin{abstract}
Background: The calcineurin B-like protein (CBL) and CBL-interacting protein kinase (CIPK) signaling system plays a key regulatory role in plant stress signaling. The roles of plant-specific CIPKs, essential for CBL-CIPK functions, in the response to various abiotic stresses have been extensively studied so far. However, until now, the possible roles of the CIPKs in the plant response to heavy metal toxicities are largely unknown.

Results: In this study, we used bioinformatic and molecular strategies to isolate 12 HsCIPK genes in Tibetan Plateau annual wild barley (Hordeum spontaneum C. Koch) and subsequently identified their functional roles in the response to heavy metal toxicities. The results showed that multiple HSCIPKs were transcriptionally regulated by heavy metal toxicities (e.g., $\mathrm{Hg}, \mathrm{Cd}, \mathrm{Cr}, \mathrm{Pb}$, and $\mathrm{Cu}$ ) and other abiotic stresses (e.g., salt, drought, aluminum, low and high temperature, and abscisic acid). Furthermore, the ectopic overexpression of each HsCIPK in rice (Oryza sativa L. cv Nipponbare) showed that transgenic plants of multiple HsCIPKs displayed enhanced tolerance of root growth to heavy metal toxicities $(\mathrm{Hg}, \mathrm{Cd}, \mathrm{Cr}$, and $\mathrm{Cu}$ ), salt and drought stresses. These results suggest that HsCIPKs are involved in the response to heavy metal toxicities and other abiotic stresses.
\end{abstract}

Conclusions: Tibetan Plateau annual wild barley HsCIPKs possess broad applications in genetically engineering of rice with tolerance to heavy metal toxicities and other abiotic stresses.

Keywords: Abiotic stresses, Cloning, Heavy metal toxicity, HsCIPKs, Overexpression, Tibetan plateau annual wild barley, Rice, Transformation

\section{Background}

In plant cells, the calcium ion $\left(\mathrm{Ca}^{2+}\right)$ is involved as a second messenger in the regulation of a variety of abiotic and biotic stress responses and the formation and development of plant organs (Dodd et al. 2010). The core components of $\mathrm{Ca}^{2+}$ signaling are calcium sensors, including calmodulins (CaMs), calmodulin-like proteins (CMLs), calcium-dependent protein kinases (CDPKs), and calcineurin B-like proteins (CBLs), which bind $\mathrm{Ca}^{2+}$

\footnotetext{
* Correspondence: jwpan@|zu.edu.cn

tWeihuai Pan, Jinqiu Shen and Zhongzhong Zheng contributed equally to this work.

'MOE Key Laboratory of Cell Activities and Stress Adaptations, School of Life Sciences, Lanzhou University, Lanzhou 730000, China

Full list of author information is available at the end of the article
}

and activate downstream signaling components (Rudd and Franklin-Tong 1999; Singh and Parniske 2012; Zheng et al. 2013). Among these $\mathrm{Ca}^{2+}$-bound calcium sensors, CBLs selectively interact with plant-specific CBL-interacting protein kinases (CIPKs) and thereby form a CBL-CIPK signaling system that has been demonstrated to serve as a key regulation node during stress signaling in plants (Luan 2009; Weinl and Kudla 2009; Shen et al. 2014). Thus, dissecting the mechanisms of the CBL-CIPK signaling system is one of the research priorities in the plant stress physiology field. Due to the lack of kinase activity in CBLs, different combinations with CIPKs largely determine the specificity, diversity, and complexity of the CBL-CIPK signaling system 
(Batistic et al. 2010). Therefore, functional identification of the CIPKs in distinct plant species will enhance the better understanding of the functional roles and modes of action of the CBL-CIPK signaling system.

Bioinformatic analysis has shown that there are 26 and 31 CIPK homologous genes in the model plant genomes of Arabidopsis thaliana and rice (Oryza sativa), respectively (Kolukisaoglu et al. 2004). Recently, multiple CIPK families have been bioinformatically identified in other plant species, including poplar (Populus) (Yu et al. 2007), cotton (Gossypium spp) (Wang et al. 2016a), soybean (Glycine max) (Zhu et al. 2016), canola (Brassica napus) (Zhang et al. 2014), eggplant (Solanum melongena) (Li et al. 2016), cassava (Manihot esculenta) (Hu et al. 2015), maize (Zea mays) (Chen et al. 2011), and wheat (Triticum aestivum) (Sun et al. 2015). However, genomic analysis of the cultivated barley (Hordeum vulgare) $H \nu C I P K$ family remains lacking. Tibetan plateau wild barley, in particular, the annual wild barley (Hordeum spontaneum $\mathrm{C}$. Koch), has suffered the extreme climate and environmental conditions for a long term and therefore has evolutionally generated abundant natural variations and/or unique gene networks for stress tolerance. Due to the close genetic homology of Tibetan plateau wild barley to cultivated barley, the Tibetan plateau was recently considered to be one of the centers of domestication of cultivated barley (Dai et al. 2012). Thus, Tibetan plateau wild barley is one of the few germplasm resources to utilize wild barley CIPKs to genetically engineer rice or other crops with higher stress tolerance.

Although CIPKs have been demonstrated to function in various responses to abiotic stresses, including salt, drought, flood, wounding, abscisic acid (ABA), low and high temperature (Guo et al. 2001; Kim et al. 2003; Lee et al. 2009; Li et al. 2012; Yan et al. 2014; Zhang et al. 2014), biotic stresses, such as pathogen infection (Kurusu et al. 2010; de la Torre et al. 2013; Meteignier et al. 2017), and nutrient deficiency (Xu et al. 2006; Pandey et al. 2007; Wang et al. 2016b; Straub et al. 2017), so far, no evidence has shown that CIPKs are involved in the plant response to heavy metal toxicities, which is one of the most dangerous types of toxic species for plants and therefore for animals and humans via the food chain. Heavy metals are defined as elements having a specific gravity above five and include mercury $(\mathrm{Hg})$, cadmium $(\mathrm{Cd})$, chromium $(\mathrm{Cr})$, copper $(\mathrm{Cu})$, and lead $(\mathrm{Pb})$. Heavy metals-polluted soils cause irreversible harm to plant growth and development, and crop yield and quality (Mustafa and Komatsu 2016) due to their extremely stable and nonbiodegradable biochemical characteristics. Heavy metal ions enter the cell and tightly bind to intracellular protein enzymes by replacing specific cations from their binding sites, leading to the inactivation of enzymes and the induction of reactive oxygen species (ROS), (Sharma and Dietz 2009), which causes oxidative damage to plant cells. Recent studies have shown that $\mathrm{Ca}^{2+}$ or $\mathrm{Ca}^{2+}$-dependent signaling is involved in plant tolerance to heavy metal stresses, including $\mathrm{Cd}$ and $\mathrm{Cr}$ (Fang et al. 2014; Huang et al. 2014; Ahmad et al. 2015), and aluminum (Al) toxicity (Zhang and Rengel 1999; Lan et al. 2016). However, whether CIPKs function in $\mathrm{Ca}^{2+}$-dependent plant tolerance to heavy metal and $\mathrm{Al}$ toxicities is largely unknown.

In this study, we functionally identified the roles of 12 members of the Tibetan plateau annual wild barley $H s C I P K$ family in the response to heavy metal toxicities, including $\mathrm{Hg}, \mathrm{Cd}, \mathrm{Cr}, \mathrm{Cu}$, and $\mathrm{Pb}$, and other abiotic stresses such as salt, drought, $\mathrm{Al}$, low and high temperature, and ABA. Our results demonstrate that multiple $H s C I P K s$ are involved in plant tolerance to multiple heavy metal toxicities and salt and drought stresses.

\section{Methods}

Plant materials and growth conditions

Grains of wild barley, Tibetan Plateau annual wild barley X74 (Hordeum spontaneum C. Koch), and Nipponbare rice (Oryza sativa L. ssp. japonica) were surface sterilized by $70 \%$ ethanol for 10 min followed by $10 \% \mathrm{NaClO}$ for $30 \mathrm{~min}$ and finally 8 rinses with water. The endosperms in barley and rice grains contain a large amount of nutrients and therefore provide enough nutrients to sustain the grains for one week following germination. Thus, a simple $\mathrm{CaCl}_{2}$ solution $(0.1 \mathrm{mM} \mathrm{CaCl} 2 ; \mathrm{pH} 5.8$; Pan et al. 2004) was used for barley and rice grain germination and seedling growth. To germinate the barley grains (Pan et al. 2004), sterilized grains were germinated between two layers of wet filter papers with the $\mathrm{CaCl}_{2}$ solution for one day under darkness $\left(25^{\circ} \mathrm{C}\right)$, and the germinated grains were incubated for another four days in the $\mathrm{CaCl}_{2}$ solution under darkness $\left(25^{\circ} \mathrm{C}\right)$. To germinate the rice grain (Pan et al. 2011), sterilized grains were treated for three days under darkness $\left(4{ }^{\circ} \mathrm{C}\right)$ and subsequently incubated for 3 days at $37{ }^{\circ} \mathrm{C}$ for germination. Finally, the germinated rice grains were transferred to the $\mathrm{CaCl}_{2}$ solution and incubated for four days under light conditions (14-h light/10-h dark, $28^{\circ} \mathrm{C}$ light $/ 25{ }^{\circ} \mathrm{C}$ dark). Four-day-old barley and rice seedlings with similar root lengths were used in this study.

\section{In silico cloning, molecular cloning, and sequence analysis} of $\mathrm{HsCIPKs}$

Two approaches were used in $H s C I P K$ in silico cloning. We first used available full-length cDNAs of rice OsCIPK1 to OsCIPK31 (http://www.ncbi.nlm.nih.gov/) (accession numbers of the OsCIPK cDNAs are shown in Additional file 1: Table S1) as probes to search for their homologous genes in a full-length cDNA library of a barley cultivar (http://earth.lab.nig.ac.jp/ dclust/cgi-bin/ 
barley_pub/). Second, full-length cDNAs, conserved motif in kinase domain, and the NAF/FISL domain motif of rice OsCIPK1 to OsCIPK31 as probes were subjected to a BLAST comparison with the barley nucleotide collection (nr/nt) database (http://blast.ncbi.nlm.nih.gov/) for their homologous fragment sequences, and the subsequent resulting homologous fragment sequences were spliced in silico and extended for multiple rounds via corresponding overlapping contigs. Finally, the resulting full-length cDNAs were analyzed by DNA STAR SeqMan and Megalign software.

Reverse transcription-polymerase chain reaction(RT-PCR-) and sequencing-based approaches were used to clone the HsCIPK coding sequences (CDSs) from a total cDNA pool of the Tibetan Plateau annual wild barley X74. HsCIPK-specific primers for the RT-PCR assay (Additional file 1: Table S2) were designed based on the recovered in silico cDNA sequences of the HvCIPKs. Furthermore, 5'-RACE (rapid amplification of cDNA ends) and 3'-RACE were used to confirm individual 5 ' - and 3 '-end sequences. Finally, the resulting full-length cDNAs of individual HsCIPKs were analyzed by sequence alignment and open reading frame (ORF) comparison with OsCIPKs and AtCIPKs (Accession numbers of AtCIPK cDNAs shown in Additional file 1: Table S1). Using the Clustal W Method in DNA STAR Megalign software, cDNA sequence-based predicted amino acid sequences were used to generate a phylogenetic tree of HsCIPKs, OsCIPKs, and AtCIPKs.

\section{Chemicals and treatments}

Unless specified, all reagents were from Sigma-Aldrich. All chemical stock solutions were prepared as follows: water was used to dissolve $\mathrm{CaCl}_{2}(1 \mathrm{M}), \mathrm{NaCl}(5 \mathrm{M})$, $\mathrm{AlCl}_{3}(40 \mathrm{mM}), \mathrm{HgCl}_{2}(0.5 \mathrm{M}), \mathrm{CdCl}_{2}(10 \mathrm{mM}), \mathrm{PbCl}_{2}$ $(10 \mathrm{mM}), \mathrm{K}_{2} \mathrm{Cr}_{2} \mathrm{O}_{7}(0.5 \mathrm{M})$, and $\mathrm{CuSO}_{4}(1 \mathrm{M})$. Abscisic acid (ABA; $10 \mathrm{mM}$ ) was first dissolved in a few drops of $1 \mathrm{M} \mathrm{KOH}$ and then diluted with water, whereas polyethylene glycol 6000 (PEG 6000) powders were directly prepared before use (see below). Unless otherwise indicated, in the qRT-PCR analysis of the transcriptionally induced expression levels of the endogenous HsCIPKs under heavy metal toxicities and other abiotic stresses, the final working concentrations were $400 \mathrm{mM}$ for $\mathrm{NaCl}$, $1 \mathrm{mM}$ for $\mathrm{CuSO}_{4}, 0.5 \mathrm{mM}$ for $\mathrm{K}_{2} \mathrm{Cr}_{2} \mathrm{O}_{7}, 20 \mu \mathrm{M}$ for $\mathrm{HgCl}_{2}, \mathrm{PbCl}_{2}, \mathrm{CdCl}_{2} \mathrm{AlCl}_{3}$, and $\mathrm{ABA}$, and $20 \%(w / v)$ for PEG 6000. In the root growth assay of rice transgenic lines, based on the effects of different concentrations on root elongation in the wild-type Nipponbare rice (Additional file 1: Figure S1), the final working concentrations were $50 \mathrm{mM}$ for $\mathrm{NaCl}, 50 \mu \mathrm{M}$ for $\mathrm{AlCl}_{3}$, $5 \mu \mathrm{M}$ for $\mathrm{K}_{2} \mathrm{Cr}_{2} \mathrm{O}_{7}, \mathrm{PbCl}_{2}$, and $\mathrm{CdCl}_{2}, 1 \mu \mathrm{M}$ for $\mathrm{ABA}$, $0.5 \mu \mathrm{M}$ for $\mathrm{HgCl}_{2}, 0.25 \mu \mathrm{M}$ for $\mathrm{CuSO} 4$, and $10 \%(w / v)$ for PEG 6000. All stock solutions of these chemicals were diluted to the working solutions in a simple $\mathrm{CaCl}_{2}$ solution $\left(0.1 \mathrm{mM} \mathrm{CaCl}_{2} ; \mathrm{pH} 5.8\right)$, whereas PEG 6000 powders were directly dissolved in a simple $\mathrm{CaCl}_{2}$ solution (0.1 $\mathrm{mM} \mathrm{CaCl} 2 ; \mathrm{pH} 5.8$ ) to $10 \%$ and $20 \%$ (w/v; working concentration) before use. In addition, the time lengths of all the treatments, including temperature $\left(4{ }^{\circ} \mathrm{C}\right.$ and $\left.35^{\circ} \mathrm{C}\right)$, are indicated in the text.

\section{Quantitative real-time RT-PCR (qRT-PCR) assay}

To examine the effects of heavy metal toxicities and other abiotic stresses on the transcriptional expression levels of endogenous HsCIPKs in Tibetan Plateau annual wild barley, whole seedlings or roots after treatment were used to isolate the total RNAs using an RNeasy Plant Mini Kit (Qiagen). The first-strand synthesis of cDNA was synthesized with a SuperScript III FirstStrand Synthesis System (Invitrogen). The qRT-PCR assay was performed with Thunderbird SYBR qPCR mix (Toyobo) and a StepOnePlus Real-Time PCR System (Applied Biosystems). The reactions were performed in a $20-\mu \mathrm{L}$ volume containing $10 \mu \mathrm{L} 2 \times$ SYBR qPCR mix (Toyobo), $10 \mathrm{ng} \mathrm{cDNA}$, and $1 \mu \mathrm{M}$ of each gene-specific primer (Additional file 1: Table S3). The PCR cycles were performed as follows: one cycle of $95{ }^{\circ} \mathrm{C}$ for $3 \mathrm{~min}$, 40 cycles of $95{ }^{\circ} \mathrm{C}$ for $5 \mathrm{~s}$ and $60{ }^{\circ} \mathrm{C}$ for $50 \mathrm{~s}$. The resulting data were collected and analyzed using the StepOne Software v2.1. The transcriptional levels were normalized to the housekeeping gene HvActin (Additional file 1: Table S3). For each $H s C I P K$, the transcription levels upon stress treatment for different time lengths were presented as relative values of the 0 -h time point (mock control; set as 1.0). For statistical analysis (Student's t-test, two tails; type 2), the transcription levels from three independent experiments at different time-points were compared with those of the mock control.

\section{Constructs, transformation and molecular identification in rice}

To overexpress each $H s C I P K$ gene in rice, constructs of $35 S:: H s C I P K s$ were generated individually using PCR, restriction digestion, and ligation with the plant transformation vector pCAMBIA2300S containing a $2 \times$ CAMV $35 S$ promoter and a kanamycin-resistant marker (Xiong and Yang 2003). Finally, the resulting constructs were confirmed by sequencing. All the primer sequences for the HsCIPK constructs are indicated in Additional file 1: Table S2.

For rice transformation, Nipponbare rice mature embryos were used as the initial materials for callus induction. Briefly, surface-sterilized mature embryos were incubated on agar plates containing N6D media (Ozawa 2009; Toki et al. 2006) for callus induction. Light yellow, compact and hard calluses were used in the Agrobacterium-mediated transformation with 
Agrobacterium tumefaciens EHA105 (Hiei and Komari 2008). Kanamycin-resistant vigorous calluses were recovered on selection solid media containing G418 (150 mg/L; Amresco) due to high-level kanamycin-resistance in the wild-type rice background (Dekeyser et al. 1989) and subsequently transferred to differentiation solid media with G418 (100 mg/L) for green shoot induction. Finally, the roots were induced on solid rooting media with G418 (70 mg/L). After acclimatization, regeneration plantlets (T1 generation) were cultivated in hydroponic conditions.

To determine whether these transgenic plants harboring 35S::HsCIPK constructs are true overexpression lines, a RT-PCR assay was performed in T1 generation plants. RNA isolation and cDNA synthesis were conducted as described. RT-PCR primers were designed in the OsCIPK nonhomologous region of HsCIPKs (Additional file 1: Table S4). Rice OsActin2, a housekeeping gene, was used as an internal control (Additional file 1: Table S4), whereas the wild-type Nipponbare cDNA sample served as a negative control (NC). Twenty-seven cycles of PCR were used to amplify all the exogenous $H s C I P K s$ and the endogenous OsActin2 in the rice transgenic lines. Homozygous lines for all the transgenic lines overexpressing each $H s C I P K$ were recovered in the $\mathrm{T} 3$ generation via G418-resistent selection.

\section{Root length measurement}

To determine the roles of the HsCIPKs in the plant response to heavy metal toxicities and other abiotic stresses, primary root growth was used to examine the effect of $H s C I P K$ overexpression on the plant growth response to stress treatments. To quantify root elongation, the primary root lengths were individually measured before $(0 \mathrm{~h})$ and after $24 \mathrm{~h}$ of treatment. To reduce differential physiological effects on root growth before treatment $(0 \mathrm{~h})$, root relative elongation rates (RERs; \%) were used to evaluate the stress effects on root growth. The RERs were estimated according to the following formula as previously described (Pan et al. 2004; Pan et al. 2011): $R E R=\left(\mathrm{RL}_{\mathrm{T} 24 \mathrm{~h}}-\mathrm{RL}_{\mathrm{T} 0 \mathrm{~h}}\right) /\left(\mathrm{RL}_{\mathrm{M} 24 \mathrm{~h}}{ }^{-}\right.$ $\left.\mathrm{RL}_{\mathrm{MOh}}\right) \times 100 \%$. $\mathrm{RL}_{\mathrm{T} 0 \mathrm{~h}}$ and $\mathrm{RL}_{\mathrm{T} 24 \mathrm{~h}}$ indicate root lengths $(\mathrm{RL} ; \mathrm{mm})$ before $(0 \mathrm{~h})$ and after the 24 -h stress treatment, respectively, whereas $R L_{M 0 h}$ and $R L_{M 24 h}$ represent the root lengths before $(0 \mathrm{~h})$ and after $24 \mathrm{~h}$ of mock treatment, respectively. The quantitative data of 45 seedlings for each treatment from three independent experiments were statistically evaluated using a Student's $t$-test (two tails; type 2) compared with the nontransgenic regeneration lines (NT; as the wild-type control). Multiple transgenic lines for each construct were examined in the stress treatment and the representative lines are presented.

\section{Results}

\section{In silico assay of cultivated barley HvCIPKs}

To obtain the HvCIPK cDNA sequences of cultivated barley, we performed an in silico assay to search for the corresponding homologous CIPKs in a full-length cDNA library of cultivated barley using the full-length cDNAs of rice OsCIPK1 to OsCIPK31 (Kolukisaoglu et al. 2004) as probes and subsequently recovered five rice homologous sequences of HvCIPKs, including CIPK2, $-9,-11,-23$, and -28 .

Next, we used conserved motifs in the kinase and NAF/FISL domains of the OsCIPKs combined with full-length cDNAs of OsCIPK1 to OsCIPK31 to BLAST homologous sequences in a nonredundant nucleotide database of cultivated barley and finally obtained eight rice homologous sequences of $H \nu C I P K s$, including CIPK5, $-14,-15,-17,-24,-29,-30$, and -31 . Thus, we obtained 13 potential $H \nu C I P K$ cDNA sequences.

\section{Molecular cloning of the HsCIPKs in Tibetan plateau annual wild barley}

To clone the HsCIPK CDS from the Tibetan Plateau annual wild barley, we used these $13 H \nu C I P K$ CDS sequences, combined with RT-PCR- and sequencing-based approaches, to isolate their homologous sequences from a total cDNA pool of Tibetan Plateau annual wild barley. We finally recovered 13 corresponding full-length CDS sequences of HsCIPKs. Previous findings indicated that plant-specific CIPKs possess typical conserved domains, including a kinase domain (activation loop) at the $\mathrm{N}$ terminal, a CBL-interacting domain (NAF/FISL motif), and a protein-phosphatase interaction (PPI) domain at the C terminal (Ohta et al. 2003). Analysis of the functional domain prediction confirmed that all of the 13 HsCIPKs indeed contain a conserved activation loop, an NAF/FISL motif, and a PPI domain (Fig. 1a) similar to the rice and Arabidopsis CIPKs (Additional file 1: Figure S2; HsCIPK5 as an example). Phylogenetic analysis of the deduced amino acid sequences showed that these 13 $\mathrm{HsCIPKs}$ were evolutionally divided into three branches, including (I) HsCIPK2, - 5, - 11, - 14, - 15, - 28, and 30, (II) HsCIPK9, $-17,-23,-24$, and -31 , and (III) HsCIPK29 (Fig. 1b). It is noteworthy that HsCIPK14 has an almost identical sequence to HsCIPK15 except for an additional four amino acids at its 3 '-end, similar to the rice and Arabidopsis CIPK14/CIPK15 (Kolukisaoglu et al. 2004), and therefore, only the HsCIPK14 gene was used in the following studies. In addition, except for HsCIPK15, 12 other HsCIPKs CDS and their deduced amino acid sequences have been deposited into the GenBank (Additional file 1: Figure S3a).

Next, we analyzed amino acid sequence homologies between the HsCIPKs versus the OsCIPKs and AtCIPKs. The results showed that the HsCIPKs share higher 


\section{a}

\begin{tabular}{|l|l|l|}
\hline Activation loop & NAF motif & PPI \\
\hline
\end{tabular}

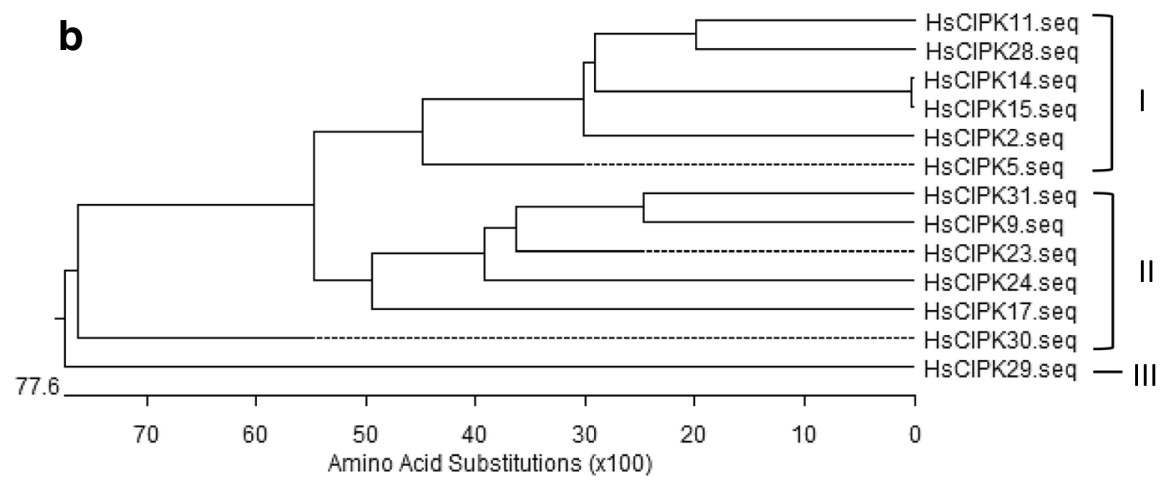

Fig. 1 Schematic diagram and sequence analysis of HsClPKs. a Prediction of functional domains in HsClPKs. b Phylogenetic analysis of 13 HsCIPKs

homology with the OsCIPKs ( 70\% to $\sim 95 \%)$ than the AtCIPKs $(\sim 46 \%$ to $\sim 77 \%)$ at the amino acid level (Additional file 1: Figure $\mathrm{S} 3 \mathrm{~b}$ and $\mathrm{c}$ ). Consistently, phylogenetic tree analysis among the HsCIPKs, OsCIPKs, and AtCIPKs showed that the individual HsCIPKs and corresponding homologous OsCIPKs were located at the identical branches, whereas the AtCIPKs were distributed at the side branches (Additional file 1: Figure S4). These results suggest that the HsCIPKs have a closer genetic relationship to the OsCIPKs than to the AtCIPKs. Thus, we designated the $H s C I P K$ numbers with the corresponding homologous OsCIPK number.

\section{Responses of HsCIPKs to heavy metal toxicities}

It is well known that plant CIPKs function in the regulation of various abiotic and biotic responses (Guo et al. 2001; de la Torre et al. 2013). However, whether CIPKs are involved in the plant response to heavy metal toxicities is largely unknown. To this end, we performed a time-course qRT-PCR analysis to examine whether heavy metal toxicities influence the transcriptional expression levels of the endogenous HsCIPKs in the Tibetan Plateau annual wild barley seedlings treated with $\mathrm{HgCl}_{2}(20 \mu \mathrm{M}), \mathrm{CdCl}_{2}(20 \mu \mathrm{M}), \mathrm{K}_{2} \mathrm{Cr}_{2} \mathrm{O}_{7}(0.5 \mathrm{mM})$, $\mathrm{PbCl}_{2}(20 \mu \mathrm{M})$, and $\mathrm{CuSO}_{4}(1 \mathrm{mM})$, respectively. As shown in Fig. 2a, upon seedling exposure to $\mathrm{HgCl}_{2}$ treatment, the transcriptional levels of 10 genes (HsCIPK2, $11,14,17,23,24,28,29,30$, and 31) were dramatically elevated relative to the mock control ( $0 \mathrm{~h}$ time point). Consistently, the expression levels of 10 genes (HsCIPK2, 9, 11, 14, 17, 23, 24, 29, 30, and 31) in the $\mathrm{CdCl}_{2}$ treatment (Fig. 2b), 10 genes (HsCIPK2, 5, 9, 11, 14, 17, 23, 24, 29, and 30) in the $\mathrm{K}_{2} \mathrm{Cr}_{2} \mathrm{O}_{7}$ treatment
(Fig. 2c), five genes (HsCIPK9, 14, 17, 24, and 29) in the $\mathrm{PbCl}_{2}$ treatment (Fig. 3a), and eight genes (HsCIPK2, $5,11,17,23,29,30$, and 31) in the $\mathrm{CuSO}_{4}$ treatment (Fig. 3b) were significantly increased compared to those in the corresponding mock control $(0 \mathrm{~h}$ time point). In addition, the maximum induction levels of all 12 endogenous HsCIPKs during each heavy metal treatment are briefly summarized in Additional file 1: Table S5, whereas these $H s C I P K s$ that were transcriptionally three times higher than the mock control are presented in Figs. 2 and 3. These results suggest that the $H s C I P K s$ respond transcriptionally to heavy metal toxicities.

\section{Responses of HsCIPKs to other abiotic stresses}

In additional to heavy metal toxicities, we also examined the effects of other abiotic stresses on the transcriptional expression levels of these $12 \mathrm{HsCIPKs}$ in the Tibetan Plateau annual wild barley seedlings, including treatments with $\mathrm{NaCl}(400 \mathrm{mM})$, polyethylene glycol 6000 (PEG 6000; 20\%; artificial drought), $\mathrm{AlCl}_{3}(20 \mu \mathrm{M})$, low and high temperature $\left(4{ }^{\circ} \mathrm{C}\right.$ and $\left.35{ }^{\circ} \mathrm{C}\right)$, and $\mathrm{ABA}$ $(20 \mu \mathrm{M})$, respectively. Time-course analysis showed that the transcriptional levels of seven genes $(H s C I P K 2,5,17$, 24, 29, 30, and 31) in the $\mathrm{NaCl}$ treatment (Fig. 4a), three genes (HsCIPK9, 29, and 31) in the PEG6000 treatment (Fig. 4b), five genes (HsCIPK24, 28, 29, 30, and 31) in the $\mathrm{AlCl}_{3}$ treatment (Fig.3c), three genes (HsCIPK9, 30 and 31) in the $4{ }^{\circ} \mathrm{C}$ treatment (Fig. 4c), two genes (HsCIPK5 and 9) in the $35{ }^{\circ} \mathrm{C}$ treatment (Fig. 4d), and three genes $(H s C I P K 2,17$, and 31) in the ABA treatment (Fig. 4e) were significantly elevated relative to the corresponding mock control ( $0 \mathrm{~h}$ time point). Furthermore, 

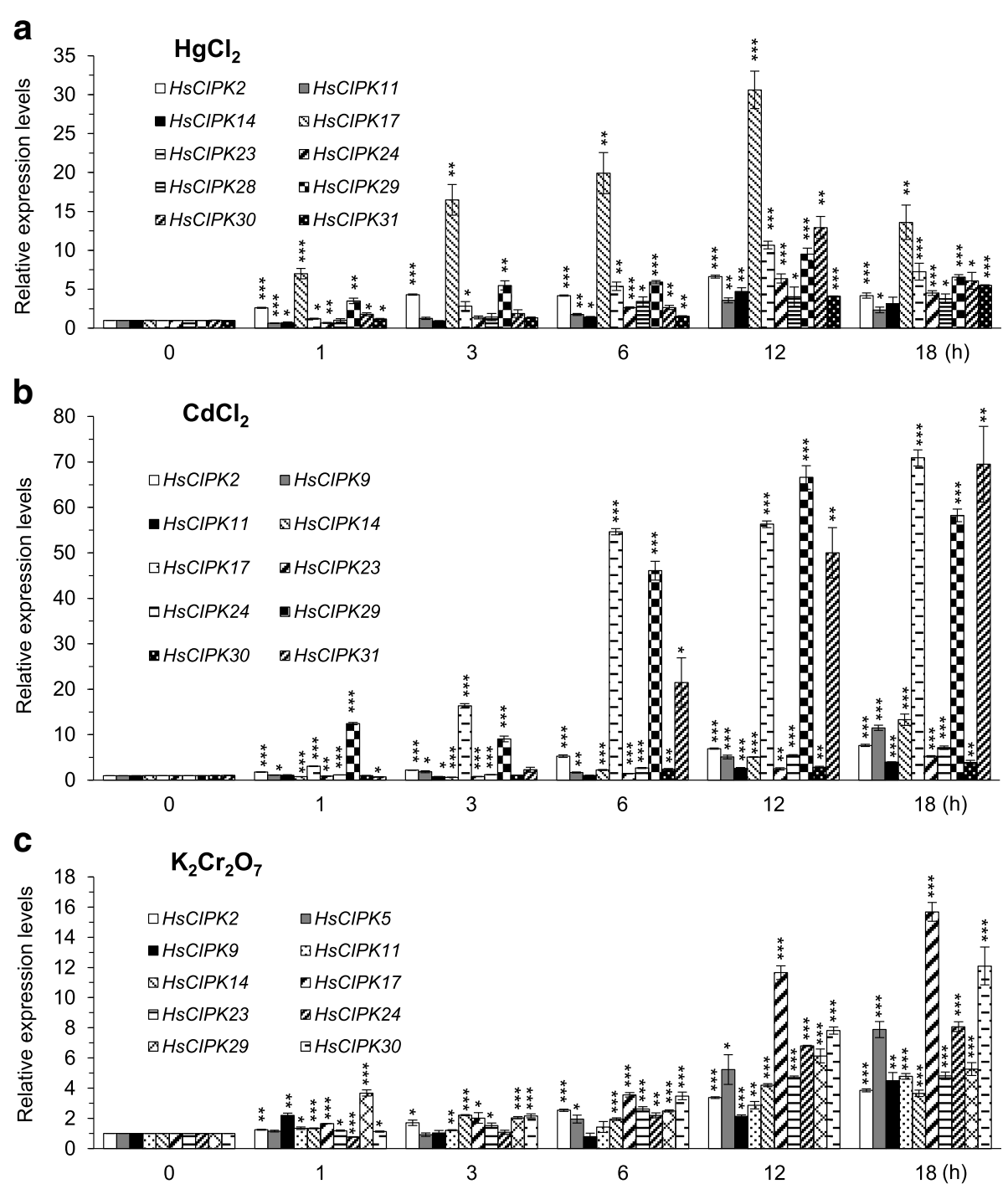

Fig. $2 \mathrm{Hg}$-, Cd-, and Cr-induced expression patterns of HsCIPKs. a-c Relative expression levels of HsCIPKs in four-day-old wild barley seedlings treated for different time lengths $\left(0,1,3,6,12\right.$, and $18 \mathrm{~h}$ ) with $20 \mu \mathrm{M} \mathrm{HgCl} 2(\mathbf{a}), 20 \mu \mathrm{M} \mathrm{CdCl}$ (b), and $0.5 \mathrm{mM} \mathrm{K}_{2} \mathrm{Cr}_{2} \mathrm{O}_{7}$ (c), respectively. Values shown are means \pm SD. Single, double, and triple asterisks indicate $P<0.01,0.001$, and 0.0001 , respectively ( $t$ test; compared to the corresponding 0 -time point mock control). The expression level of the 0-time point mock control for each HsCIPK was set as 1.0

the maximum expression levels of all 12 endogenous HsCIPKs during salt, PEG, $\mathrm{AlCl}_{3}$, temperature $\left(4{ }^{\circ} \mathrm{C}\right.$ and $35^{\circ} \mathrm{C}$ ), and ABA treatments are briefly summarized in Additional file 1: Table S6, whereas their induction levels, which were two times higher than the mock control are presented in Figs. 3c and 4. These results further confirmed the involvement of HsCIPKs in multiple abiotic stress responses.

\section{Generation of rice transgenic lines overexpressing HsCIPKs}

To provide further evidence for the roles of HsCIPKs in the plant response to heavy metal toxicities and other abiotic stresses, rice transgenic lines overexpressing individual HsCIPKs under the control of the CAMV $35 \mathrm{~S}$ promoter were generated in the wild-type rice cultivar Nipponbare (Oryza sativa L. ssp. japonica) (Fig. 5a-c), which is a good transformation system and additionally possesses a closer genetic relationship to the wild barley than Arabidopsis at the CIPK levels (Additional file 1: Figsure S3 and S4). A RT-PCR assay with $H s C I P K$-specific PCR primers was used to examine the overexpression levels of the exogenous $H s C I P K$ genes in the T1 generation plants. As shown in Additional file 1: Figure S5, multiple overexpression transgenic lines for each $H s C I P K$ construct were recovered. In the T3 generation, homozygous transgenic lines with no further segregation were recovered via G418-resistant selection. 

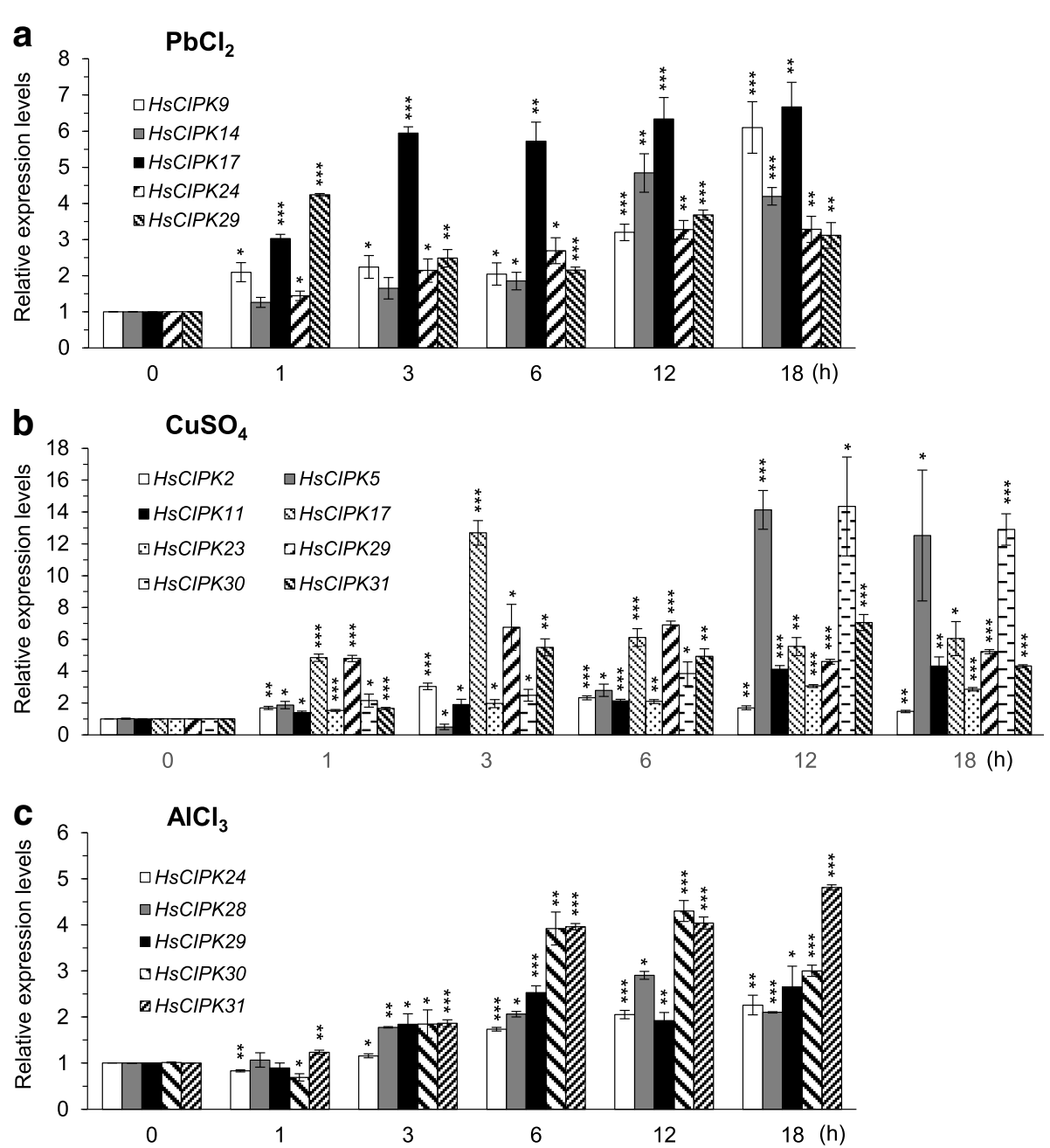

Fig. $3 \mathrm{~Pb}-, \mathrm{Cu}$-, and Al-induced expression patterns of HsCIPKs. a-c Relative expression levels of HsCIPKs in four-day-old wild barley seedlings treated for different time lengths $(0,1,3,6,12$, and $18 \mathrm{~h})$ with $20 \mu \mathrm{M} \mathrm{PbCl}_{2}(\mathbf{a}), 1 \mathrm{mM} \mathrm{CuSO}{ }_{4}(\mathbf{b})$, and $20 \mu \mathrm{M} \mathrm{AlCl}$ (c), respectively. Values shown are means \pm SD. Single, double, and triple asterisks indicate $P<0.01,0.001$, and 0.0001 , respectively ( $t$ test; compared to the corresponding 0 -time point mock control). The expression level of the 0-time point mock control for each HsCIPK was set as 1.0

Functional analysis of $\mathrm{HsCIPK}$ overexpression in response to heavy metal toxicities

In plants, heavy metal toxicity-induced symptoms include the inhibition of seed germination and root elongation, wilting and stunted plant growth, chlorosis, leaf rolling and necrosis, and senescence, as well as low biomass (DalCorso et al. 2013), among which root elongation inhibition is an early symptom of heavy metal-induced responses. Thus, root elongation has been widely used as a sensitive indicator for plant responses to heavy metal toxicities (Wong and Bradshaw 1982) and other abiotic stresses (Llugany et al. 1995; Ishikawa et al. 1998). In this study, the relative elongation rate (RER; \%) of the primary root was used to evaluate the root growth response to heavy metal toxicities. Heavy metal treatment experiments with different concentrations in four-day-old wild-type Nipponbare seedlings revealed that $0.5 \mu \mathrm{M} \mathrm{HgCl}_{2}, 5 \mu \mathrm{M} \mathrm{CdCl}$, $5 \mu \mathrm{M} \mathrm{K} \mathrm{Kr}_{2} \mathrm{O}_{7}, 0.25 \mu \mathrm{M} \mathrm{CuSO}$, and $5 \mu \mathrm{M} \mathrm{\textrm {PbCl } _ { 2 }}$ were suitable to examine the effects of $H s C I P K$ overexpression on root growth response to heavy metal toxicities (Additional file 1: Figure S1). Upon transgenic seedling exposure to $\mathrm{HgCl}_{2}$ treatment for $24 \mathrm{~h}$, the overexpression of $H s C I P K 2, H s C I P K 14$, and $H s C I P K 17$ significantly enhanced root growth relative to the corresponding wild-type controls (nontransgenic regeneration lines; NT) (Fig. 5d). Similarly, transgenic lines individually overexpressing seven $H s C I P K s$ (HsCIPK9, 11, 14, 17, 23, 24, and 29) in the $\mathrm{CdCl}_{2}$ treatment (Fig. 5e), five HsCIPKs (HsCIPK2, 5, 9, 17, and 30) in the $\mathrm{K}_{2} \mathrm{Cr}_{2} \mathrm{O}_{7}$ treatment (Fig. 5f), and four HsCIPKs (HsCIPK5, 24, 29, and 31) in the $\mathrm{CuSO}_{4}$ 

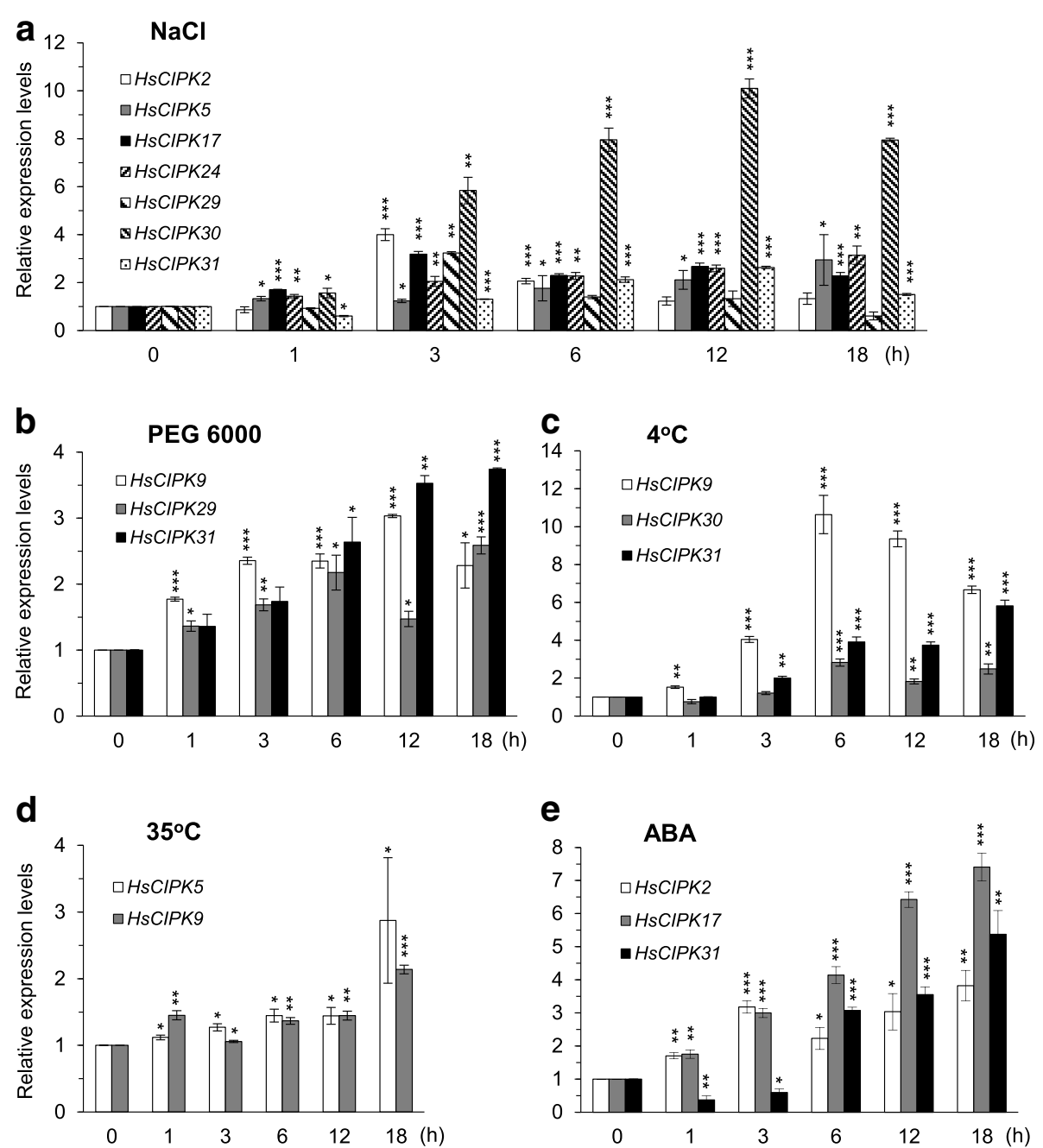

Fig. 4 Salt-, drought-, temperature-, and ABA-induced expression patterns of HSCIPKs. a-e Relative expression levels of HsCIPKs in four-day-old wild barley seedlings treated for different time lengths $(0,1,3,6,12$, and $18 \mathrm{~h})$ with $400 \mathrm{mM} \mathrm{NaCl}(\mathbf{a}), 20 \% \mathrm{PEG} 6000(\mathbf{b}), 4^{\circ} \mathrm{C}(\mathbf{c}), 35^{\circ} \mathrm{C}(\mathbf{d})$, and $20 \mu \mathrm{M}$ ABA (e), respectively. Values shown are means \pm SD. Single, double, and triple asterisks indicate $P<0.01,0.001$, and 0.0001 , respectively ( $t$ test: compared to the corresponding 0 -time point mock control). The expression level of the 0-time point mock control for each HsCIPK was set as 1.0

treatment (Fig. 5g) displayed a significant elevation in root growth relative to the corresponding $\mathrm{NT}$. In the $\mathrm{PbCl}_{2}$ treatment, surprisingly, no transgenic lines displayed enhanced effects in root growth relative to the NT (Fig. 5h). In contrast, the transgenic lines overexpressing $H s C I P K 31$ in the $\mathrm{K}_{2} \mathrm{Cr}_{2} \mathrm{O}_{7}$ treatment (Fig. 5f) and $H s C I P K 17,28,29$, and 30 in the $\mathrm{PbCl}_{2}$ treatment (Fig. 5h), respectively, exhibited a significant reduction in root growth compared to the corresponding NT. The responses of root growth to these heavy metal toxicities in the transgenic lines of all 12 $H s C I P K s$ are summarized in Additional file 1: Table S7. Taken together, these results suggest that multiple $H s C I P K s$ are involved in the plant response to heavy metal toxicities.
Functional analysis of $\mathrm{HsCIPK}$ overexpression in response to other abiotic stresses

Next, to test whether the overexpression of $H s C I P K s$ enhances plant tolerance to other abiotic stresses, we examined root growth of four-day-old transgenic rice seedlings treated for $24 \mathrm{~h}$ with salt $(50 \mathrm{mM} \mathrm{NaCl})$, drought (10\% PEG6000), ABA $(1 \mu \mathrm{M})$, and $\mathrm{AlCl}_{3}$ $(50 \mu \mathrm{M})$ (Additional file 1: Figure $\mathrm{S} 1$ ), respectively. As shown in Fig. 6a-c, upon transgenic seedling exposure to $\mathrm{NaCl}, \mathrm{PEG6000}$, and ABA treatments, respectively, the overexpression lines for six HsCIPKs $(H s C I P K 2,5,17$, 28, 29, and 30) in the $\mathrm{NaCl}$ treatment, four $H s C I P K s$ (HsCIPK17, 23, 29, and 31) in PEG 6000 treatment, and two HsCIPKs (HsCIPK2 and 17) in the ABA treatment displayed a significantly enhanced effect on root growth 
a
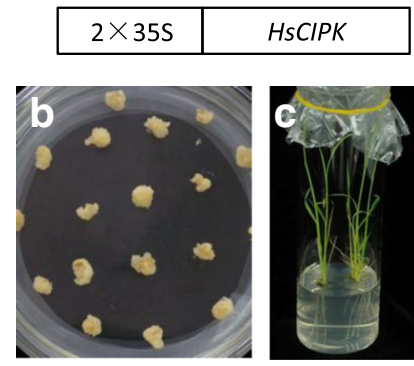

e

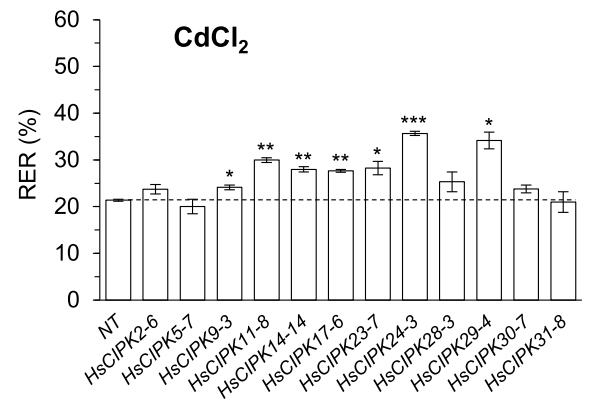

g

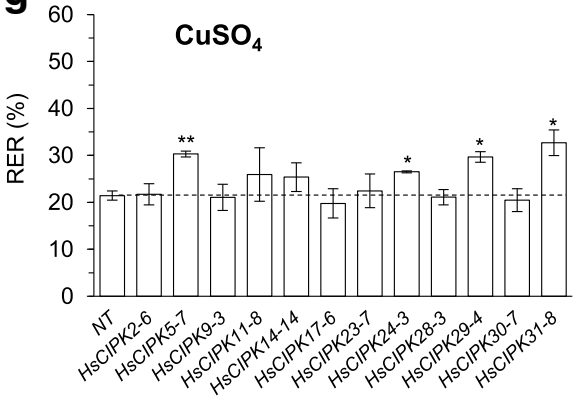

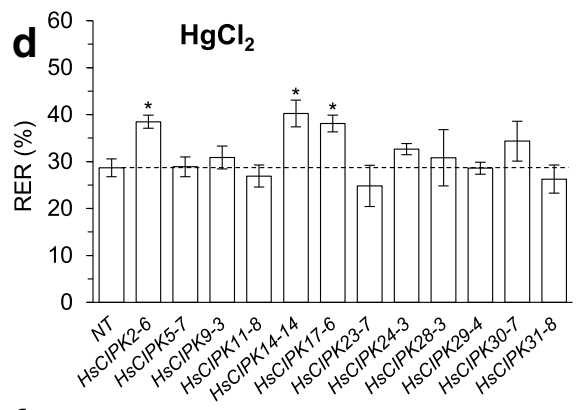

f

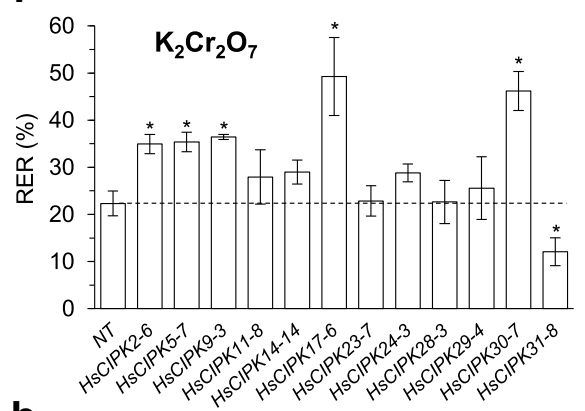

h

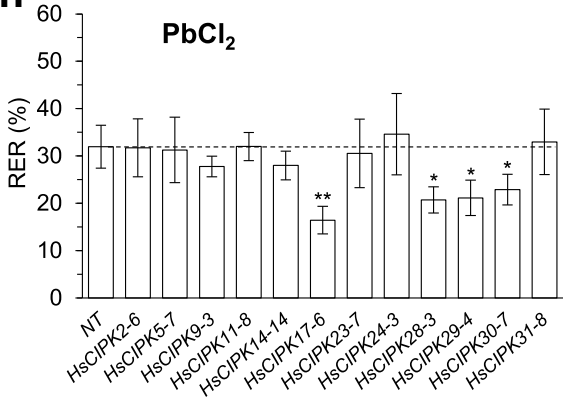

Fig. 5 Effects of heavy metal toxicities on root growth in rice seedlings overexpressing HsCIPKS. a-c Construct for HsCIPK overexpression (a), callus induction in rice mature embryos (b), and transgenic plants (c). d-h Root relative elongation rates (\%; RER) of four-day-old rice seedlings overexpressing HsCIPKs treated for $24 \mathrm{~h}$ with $0.5 \mu \mathrm{M} \mathrm{HgCl}$ (d), $5 \mu \mathrm{M} \mathrm{CdCl}_{2}(\mathbf{e}), 5 \mu \mathrm{M} \mathrm{K}_{2} \mathrm{Cr}_{2} \mathrm{O}_{7}(\mathbf{f}), 0.25 \mu \mathrm{M} \mathrm{CuSO}_{4}(\mathbf{g})$, and $5 \mu \mathrm{M} \mathrm{PbCl} 2$ (h), respectively. Values shown are means \pm SD. Single, double, and triple asterisks indicate $P<0.05,0.01$, and 0.001 , respectively ( $t$ test; compared to the wild-type control NT seedlings). $N T$, nontransgenic regeneration lines

relative to the corresponding NT, indicating a positive role of these HsCIPKs in plant tolerance to salt and drought stresses and ABA treatment. However, in the $\mathrm{AlCl}_{3}$ treatment, no transgenic lines showed an enhanced effect on root growth relative to the NT (Fig. 6d). In contrast, the transgenic lines overexpressing two HsCIPKs (HsCIPK23 and 29) in the ABA treatment (Fig. 6c) and four HsCIPKs (HsCIPK9, 14, 17, and 30) in the $\mathrm{AlCl}_{3}$ treatment (Fig. 6d) exhibited an inhibitory effect on root growth relative to the corresponding NT, indicating a negative role of these HsCIPKs in the plant response to $\mathrm{ABA}$ and $\mathrm{AlCl}_{3}$ stresses. The responses of root growth to these abiotic stresses in the transgenic lines of all $12 H s C I P K s$ are summarized in Additional file 1: Table S7. These results further confirmed the roles of $H s C I P K s$ in the plant response to salt and drought stresses.

\section{Discussion}

Previous studies have demonstrated that plant-specific CIPKs function in plant responses to various abiotic and biotic stresses, including salt, drought, low and high temperature, wounding, low oxygen, and pathogen infection (Shen et al. 2014; Yu et al. 2014). However, the evidence for whether CIPKs are involved in the plant esponse to heavy metal toxicities currently remains lacking. In this study, we used an in silico assay and a molecular cloning strategy to isolate $12 \mathrm{HsCIPKs}$ from Tibetan Plateau annual wild barley and subsequently examined the heavy metal toxicity-induced expression patterns of 12 endogenous HsCIPK genes and determined the role of their overexpression in the rice response to multiple heavy metal toxicities and other abiotic stresses. 

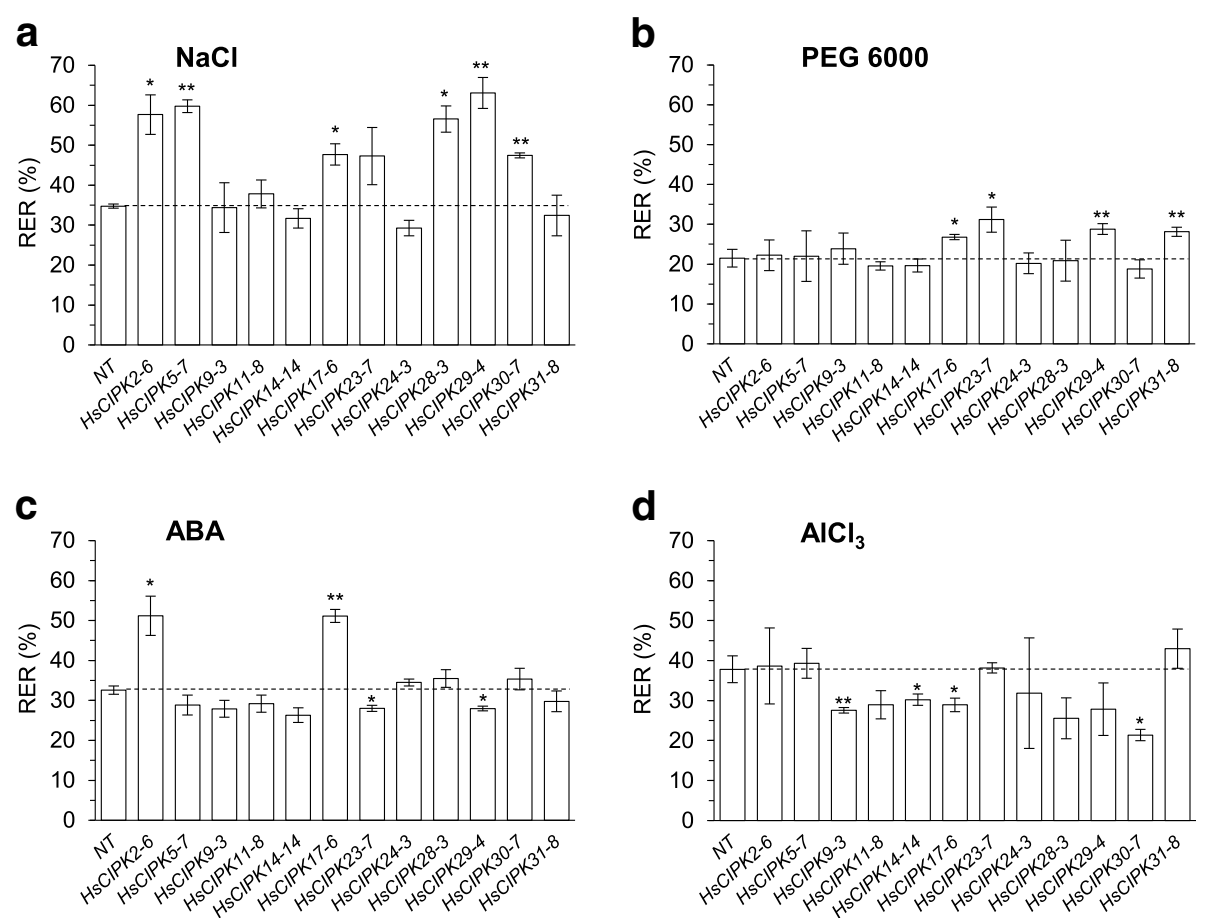

Fig. 6 Effects of salt, drought, $A B A$, and Al treatments on root growth in rice seedlings overexpressing HsCIPKs. a-d Root relative elongation rates (\%; RER) of four-day-old rice seedlings overexpressing HsCIPKs treated for $24 \mathrm{~h}$ with $50 \mathrm{mM} \mathrm{NaCl}$ (a), 10\% PEG6000 (b), $1 \mu \mathrm{M}$ ABA (c), and $50 \mu \mathrm{M}$ $\mathrm{AlCl}_{3}(\mathbf{d})$, respectively. Values shown are means $\pm \mathrm{SD}$. Single and double asterisks indicate $\mathrm{P}<0.05$ and 0.01 , respectively ( $t$ test; compared to the wild-type control NT seedlings). NT, nontransgenic regeneration lines

\section{Heavy metal toxicities induce transcriptional expression of multiple $\mathrm{HsCIPKs}$}

Our time-course qRT-PCR analysis (Figs. 2, 3 and 4; Additional file 1: Tables S5 and S6) revealed that all of the 12 endogenous $H s C I P K s$ examined can be induced by multiple heavy metal toxicities, including $\mathrm{Hg}, \mathrm{Cd}, \mathrm{Cr}$, $\mathrm{Pb}$, and $\mathrm{Cu}$, and in addition, nine HsCIPKs (except for HsCIPK11, 14, and 23) are also induced by multiple other abiotic stresses, including salt, drought, cold, heat, and $\mathrm{Al}$ stresses, and ABA treatment. Heavy metal treatment experiments (Figs. 2 and 3; Additional file 1: Table S5) showed that HsCIPK17 and 29 can be highly induced by all five heavy metal toxicities examined, whereas $H s C I P K 2,11,14,23,24$, and 30 are highly induced by four heavy metal toxicities. In addition, HsCIPK9 and 31 are also highly induced by three heavy metal toxicities. In addition to the response to heavy metal toxicities, HsCIPKs also respond to other abiotic stresses, including salt, drought, temperature, and $\mathrm{Al}$ stresses. Of note, the transcriptional induction levels corresponding to these stresses (Fig. 4; Additional file 1: Table S6) are relatively low compared to those corresponding to heavy metals (Figs. 2 and 3; Additional file 1: Table S5). These data suggest that multiple $H s C I P K s$ are involved in the plant response to heavy metal toxicities and other abiotic stresses.
Previous studies have shown that wheat TaCIPK14 and Arabidopsis AtCIPK14 are upregulated by treatments with salt, PEG, and ABA (Deng et al. 2013; Yan et al. 2014). In contrast, our treatment experiments (Additional file 1: Tables S5 and S6; Figs. 2 and 3) revealed that HsCIPK14 is downregulated by salt, PEG, heat, and ABA treatments but upregulated by multiple heavy metal toxicities, including $\mathrm{Hg}, \mathrm{Cd}, \mathrm{Cr}$, and $\mathrm{Pb}$. Similarly, Brachypodium distachyon BdCIPK31 was found to be downregulated by salt, PEG, $\mathrm{H}_{2} \mathrm{O}_{2}$, and ABA treatments (Luo et al. 2017), whereas $H s C I P K 31$ is upregulated by not only salt, PEG, ABA, Al, and cold treatments but also multiple heavy metal toxicities, including $\mathrm{Hg}, \mathrm{Cd}$, and $\mathrm{Cu}$ (Figs. 2, 3 and 4; Additional file 1: Tables S5 and S6). These different responses clearly reflect the functional divergence of the CIPK paralog genes in distinct plant species in response to various abiotic stresses during long-term evolution.

\section{Overexpression of the $\mathrm{HsCIPKs}$ enhances plant tolerance to heavy metal toxicities}

The overexpression experiment in rice (Figs. 5 and 6; Additional file 1: Table S7) showed that the individual overexpression of $11 \mathrm{HsCIPKs}$ (except for HsCIPK28) promotes root growth tolerance to multiple heavy metal toxicities $(\mathrm{Hg}, \mathrm{Cd}, \mathrm{Cr}$, and $\mathrm{Cu})$, and furthermore, plants 
individually overexpressing $8 H s C I P K s$ (except for HsCIPK9, 11, 14, and 24) display enhanced tolerance of root growth to salt, drought, and $\mathrm{ABA}$ treatments, further confirming the involvement of the HsCIPKs in the plant response to heavy metal toxicities and other abiotic stresses, including salt and drought. However, we cannot rule out the possibility that the transgenic lines of some HsCIPKs with no positive role in root growth tolerance to most of stress treatments are due to their inadequate expression levels, for example, HsCIPK11 and $H s C I P K 23$ (Additional file 1: Figure S5). In addition, $\mathrm{PbCl}_{2}$ and $\mathrm{AlCl}_{3}$ treatments in wild barley significantly induce the transcriptional expression of multiple HsCIPKs (9, 14, 17, 24, 28, 29, 30, and 31; Fig. 3; Additional file 1: Tables $\mathrm{S} 5$ and S6), but the overexpression of $H s C I P K s(9,14,17,28,29$, and 30$)$ in rice inhibits the root growth tolerance to $\mathrm{Pb}$ and $\mathrm{Al}$ toxicities (Figs. 5 and 6; Additional file 1: Table S7). Similarly, the overexpression of $H s C I P K 31$ in rice inhibits the root growth tolerance to $\mathrm{Cr}$ toxicity, which does not visibly induce HsCIPK31 transcriptional expression (Fig. 5; Additional file 1: Tables S6 and S7). Although Al and heavy metal toxicities affect plant root growth differentially, our results clearly indicate that these HsCIPKs act as a negative regulator in the plant tolerance to $\mathrm{Pb}, \mathrm{Al}$, and $\mathrm{Cr}$ toxicities. This finding is similar to the previous studies showing that ABA treatment induces endogenous BnCIPK6 and AtCIPK6 expression transcriptionally, although their overexpression in Arabidopsis enhances the sensitivity to the ABA treatment (Chen et al. 2012; Chen et al. 2013), and that the loss of AtCIPK5 function mutants display an increased resistance response to pathogens (Meteignier et al. 2017), and therefore Bn/AtCIPK6 and AtCIPK5 are a negative regulator for plant tolerance to ABA treatment and pathogen attack, respectively. It is likely that during the plant response to $\mathrm{Pb}, \mathrm{Al}$, and $\mathrm{Cr}$ toxicities, these HsCIPKs with a negative role may exert feedback regulation on the positive functions of other HsCIPKs/CBLs and/or other calcium sensors (CaMs, CMLs, and CDPKs). This hypothesis will require additional study. Fortunately, a high-quality reference genome assembly for cultivated barley has been recently published (Mascher et al. 2017) and thereby will accelerate the functional identification of all HsCIPK family members.

It is widely acknowledged that multiple CIPKs in distinct plant species redundantly function in salt, drought, and ABA stress responses (Luan 2009; Weinl and Kudla 2009; Shen et al. 2014; Yu et al. 2014). Consistently, our findings (Figs. 5 and 6; Additional file 1: Table S7) reveal that the same single $H s C I P K$ is involved in the response to multiple distinct heavy metal toxicities, whereas multiple HsCIPKs function in the response to the same single heavy metal toxicity, indicating that plant-specific
CIPKs are functionally redundant in the regulation of the plant response to heavy metal toxicities. The identification of knockout or knockdown mutants for HsCIPKs will provide genetic evidence for HsCIPK function in heavy metal toxicities.

The traditional remediation strategies for heavy metals-contaminated soils primarily depend on physical and chemical methods and are expensive and relatively ineffective due to large-scale contamination farmlands and high costs. Thus, the best approaches are to genetically engineer crops with high resistance to heavy metal toxicities (Cao et al. 2014). Rice, as a primary food cereal in the world, is one of the major sources of heavy metal intakes for humans in inland China (Zhang et al. 2010), and therefore, developing rice cultivars with a higher tolerance to multiple heavy metal toxicities is critical for heavy metal-polluted soils that usually contain multiple heavy metal toxicities. Intriguingly, our results (Figs. 5 and 6; Additional file 1: Table S7) showed that the overexpression of the same single $H s C I P K$ enhances rice growth tolerance to multiple heavy metal toxicities, indicating that these identified $H_{s} C I P K s$ (2, 5, 9, 14, 17, 24, and 29) are important for genetically engineering crops with multiple heavy metal tolerances, which will have a broad application in heavy metal-contaminated soils. However, the mode of action by which HsCIPKs enhance plant tolerance to heavy metal toxicities via modulating heavy metal excretion and/or chelation mechanisms or scavenging heavy metal-induced ROS remain to be experimentally elucidated in future studies.

\section{Conclusions}

Using an in silico assay and a molecular cloning strategy to isolate $12 \mathrm{HsCIPKs}$ in Tibetan Plateau annual wild barley enabled us to the effects of heavy metal toxicities on the transcriptional expression patterns of 12 endogenous $H s C I P K$ genes and evaluate their functional roles in the response to multiple heavy metal toxicities and other abiotic stresses in rice. Multiple HsCIPKs were found to be involved in the response of plants to heavy metal toxicities, including $\mathrm{Hg}, \mathrm{Cd}, \mathrm{Cr}, \mathrm{Pb}$, and $\mathrm{Cu}$ and other abiotic stresses, including salt, drought, $\mathrm{Al}$, low and high temperature, and ABA. The ectopic overexpression of $H s C I P K 2,5,9,14,17,24$, and 29 in Nipponbare rice (Oryza sativa) enhanced the tolerance of rice root growth to multiple heavy metal toxicities, whereas the overexpression of $H s C I P K 2,5,17,23,24$, $28,29,30$, and 31 promoted root growth tolerance to salt and/or drought stresses. These results suggest that plant-specific CIPKs function in heavy metal toxicities and these HsCIPKs examined will have a broad application in genetically engineered rice and other crops with tolerance to heavy metal toxicities and other abiotic stresses. 


\section{Additional file}

Additional file 1: Figure S1. Effects of abiotic stresses on root elongation in rice. Figure S2. Alignment analysis of amino acid sequences among HsCIPK5, OsCIPK5, and AtCIPK5. Figure S3. GenBank accession numbers and homology analysis of HsCIPKs. Figure S4. Phylogenetic analysis of HsCIPKs, OsCIPKs, and AtCIPKs. Figure S5. Molecular identification of HsCIPK overexpression in rice. Table S1. Accession numbers of rice and Arabidopsis CIPK CDNA in NCBI database. Table S2. Primer sequences for HsCIPKs cloning. Table S3. Primer sequences for qRT-PCR assay in Tibetan Plateau annual wild barley. Table S4. Primer sequences for RT-PCR Assay in rice transgenic lines. Table S5. Summary of endogenous HsCIPK responses to heavy metal toxicities. Table S6. Summary of endogenous HsCIPK responses to other abiotic stresses. Table S7. Summary of root growth tolerance to abiotic stresses in rice transgenic lines overexpressing HsCIPKs. (PDF 800 kb)

\section{Abbreviations}

ABA: Abscisic acid; Al: Aluminum; $\mathrm{Ca}^{2+}$ : Calcium; $\mathrm{CBL}$ : Calcineurin B-like protein; Cd: Cadmium; CDS: Coding sequence; CIPK: CBL-interacting protein kinase; Cr: Chromium; Cu: Copper; Hg: Mercury; NAF/FISL: Conserved amino acid motif NAF/FISL; NC: Negative control; NT: Nontransgenic regeneration lines; Pb: Lead; PEG 6000: Polyethylene glycol 6000; PPI: Protein-phosphatase interaction domain; qRT-PCR: Quantitative Real-Time PCR; RER: Relative elongation rates; RT-PCR: Reverse transcription-polymerase chain reaction

\section{Acknowledgements}

We thank Guoping Zhang (Zhejiang University), Yinong Yang (Pennsylvania State University), and Lin Yang (Zhejiang Normal University) for sharing materials.

\section{Funding}

This study was supported by the National Science and Technology Major Program for New Varieties of Genetically Modified Crops (2009ZX08009076003), the National Natural Science Foundation of China (No. 31670283 and 91754104), the Natural Science Foundation of Zhejiang Province (No. LY16C130004 and LY17C060001), and the Fundamental Research Funds for the Central Universities (Izujbky-2017-ot16).

\section{Availability of data and materials}

All data supporting the conclusions of this article are provided within the article (and its additional files).

\section{Authors' contribution}

$W P, J S, Z Z, L J$, and JP conceived the study and designed the experiments. $W P, J S, Z Z, X Y, J S$, and $W W$ carried out the bioinformatic assays and the experiments. WP, JS, ZZ, LJ, and JP analyzed the data. WP and JP wrote the manuscript. WP, LJ, and JP revised the manuscript. All authors read and approved the final manuscript

\section{Ethics approval and consent to participate}

Not applicable.

\section{Consent for publication}

These coauthors involved in the paper all consent to publish this article on Rice.

\section{Competing interests}

The authors declare that they have no competing interests.

\section{Publisher's Note}

Springer Nature remains neutral with regard to jurisdictional claims in published maps and institutional affiliations.

\section{Author details}

${ }^{1}$ MOE Key Laboratory of Cell Activities and Stress Adaptations, School of Life Sciences, Lanzhou University, Lanzhou 730000, China. ${ }^{2}$ College of Life Sciences, Shaoxing University, Shaoxing 312000, Zhejiang, China. ${ }^{3}$ College of
Chemistry and Life Sciences, Zhejiang Normal University, Jinhua 321004, Zhejiang, China. ${ }^{4}$ Department of Agronomy, College of Agriculture and Biotechnology, Zhejiang University, Hangzhou 310058, China.

Received: 1 February 2018 Accepted: 5 September 2018

Published online: 12 September 2018

\section{References}

Ahmad A, Hadi F, Ali N (2015) Effective phytoextraction of cadmium (cd) with increasing concentration of total phenolics and free proline in Cannabis sativa $(\mathrm{L})$ plant under various treatments of fertilizers, plant growth regulators and sodium salt. Int J Phytoremed 17:56-65

Batistic O, Waadt R, Steinhorst L, Held K, Kudla J (2010) CBL-mediated targeting of CIPKs facilitates the decoding of calcium signals emanating from distinct cellular stores. Plant J 61:211-222

Cao FB, Wang RF, Cheng WD, Zeng FR, Ahmed IM, Hu XN, Zhang GP, Wu FB (2014) Genotypic and environmental variation in cadmium, chromium, lead and copper in rice and approaches for reducing the accumulation. Sci Total Environ 496:275-281

Chen L, Ren F, Zhou L, Wang QQ, Zhong H, Li XB (2012) The Brassica napus Calcineurin B-like 1/CBL-interacting protein kinase 6 (CBL1/CIPK6) component is involved in the plant response to abiotic stress and ABA signaling. J Exp Bot 63:6211-6222

Chen L, Wang OQ, Zhou L, Ren F, Li DD, Li XB (2013) Arabidopsis CBL interacting protein kinase (CIPK6) is involved in plant response to salt/osmotic stress and ABA. Mol Biol Rep 40:4759-4767

Chen XF, Gu ZM, Xin DD, Hao L, Liu CJ, Huang J, Ma BJ, Zhang HS (2011) Identification and characterization of putative CIPK genes in maize. J Genet Genomics 38:77-87

Dai F, Nevo E, Wu DZ, Comadran J, Zhou MX, Qiu L, Cheng ZH, Belles A, Chen GX, Zhang GP (2012) Tibet is one of the centers of domestication of cultivated barley. Proc Natl Acad Sci U S A 109:16969-16973

DalCorso G, Manara A, Furini A (2013) An overview of heavy metal challenge in plants: from roots to shoots. Metallomics 5:1117-1132

Dekeyser R, Claes B, Marichal M, Van Montagu M, Caplan A (1989) Evaluation of selectable markers for rice transformation. Plant Physiol 90:217-223

Deng X, Zhou S, Hu W, Feng J, Zhang F, Chen L, Huang C, Luo Q, He Y, Yang G, He G (2013) Ectopic expression of wheat TaCIPK14, encoding a calcineurin Blike protein-interacting protein kinase, confers salinity and cold tolerance in tobacco. Physiol Plant 149:367-377

Dodd AN, Kudla J, Sanders D (2010) The language of calcium signaling. Annu Rev Plant Biol 61:593-620

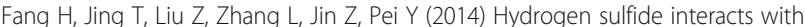
calcium signaling to enhance the chromium tolerance in Setaria italica. Cell Calcium 56:472-481

Guo Y, Halfter U, Ishitani M, Zhu JK (2001) Molecular characterization of functional domains in the protein kinase SOS2 that is required for plant salt tolerance. Plant Cell 13:1383-1400

Hiei Y, Komari T (2008) Agrobacterium-mediated transformation of rice using immature embryos or calli induced from mature seed. Nat Protoc 3:824-834

Hu W, Xia Z, Yan Y, Ding Z, Tie W, Wang L, Zou M, Wei Y, Lu C, Hou X, Wang W, Peng M (2015) Genome-wide gene phylogeny of CIPK family in cassava and expression analysis of partial drought-induced genes. Front Plant Sci 6:914

Huang TL, Huang LY, Fu SF, Trinh NN, Huang HJ (2014) Genomic profiling of rice roots with short-and long-term chromium stress. Plant Mol Biol 86:157-170

Ishikawa S, Wagatsuma T (1998) Plasma membrane permeability of root-tip cells following temporary exposure to $\mathrm{Al}$ ions is a rapid measure of Al tolerance among plant species. Plant Cell Physiol 39:516-525

Kim KN, Cheong YH, Grant JJ, Pandey GK, Luan S (2003) CIPK3, a calcium sensorassociated protein kinase that regulates abscisic acid and cold signal transduction in Arabidopsis. Plant Cell 15:411-423

Kolukisaoglu U, Weinl S, Blazevic D, Batistic O, Kudla J (2004) Calcium sensors and their interacting protein kinases: genomics of the Arabidopsis and rice CBLCIPK signaling networks. Plant Physiol 134:43-58

Kurusu T, Hamada J, Nokajima H, Kitagawa Y, Kiyoduka M, Takahashi A, Hanamata S, Ohno R, Hayashi T, Okada K, Koga J, Hirochika H, Yamane H, Kuchitsu K (2010) Regulation of microbe-associated molecular pattern induced hypersensitive cell death, phytoalexin production, and defense gene expression by calcineurin B-like protein-interacting protein kinases, OsCIPK14/ 15, in rice cultured cells. Plant Physiol 153:678-692 
Lan T, You J, Kong L, Yu M, Liu M, Yang Z (2016) The interaction of salicylic acid and $\mathrm{Ca}^{2+}$ alleviates aluminum toxicity in soybean (Glycine max L.). Plant Physiol Biochem 98:146-154

Lee KW, Chen PW, Lu CA, Chen S, Ho TH, Yu SM (2009) Coordinated responses to oxygen and sugar deficiency allow rice seedlings to tolerate flooding. Sci Signal 2:ra61. https://doi.org/10.1126/scisignal.2000333

Li J, Jiang MM, Ren L, Liu Y, Chen HY (2016) Identification and characterization of CBL and CIPK gene families in eggplant (Solanum melongena L.). Mol Gen Genomics 291:1769-1781

Li R, Zhang J, Wu G, Wang H, Chen Y, Wei J (2012) HbCIPK2, a novel CBLinteracting protein kinase from halophyte Hordeum brevisubulatum, confers salt and osmotic stress tolerance. Plant Cell Environ 35:1582-1600

Llugany M, Poschenrieder C, Barceló J (1995) Monitoring of aluminum-induced inhibition of root elongation in four maize cultivars differing in tolerance to aluminum and proton toxicity. Physiol Plant 93:265-271

Luan S (2009) The CBL-CIPK network in plant calcium signaling. Trends Plant Sci 14:37-42

Luo Q, Wei Q, Wang R, Zhang Y, Zhang F, He Y, Zhou S, Feng J, Yang G, He G (2017) BdCIPK31, a calcineurin B-like protein interacting protein kinase, regulates plant response to drought and salt stress. Front Plant Sci 8:1184

Mascher M et al (2017) A chromosome conformation capture ordered sequence of the barley genome. Nature 544:427-433

Meteignier LV, El Oirdi M, Cohen M, Barff T, Matteau D, Lucier JF, Rodrigue S, Jacques PE, Yoshioka K, Moffett P (2017) Translatome analysis of an NB-LRR immune response identifies important contributors to plant immunity in Arabidopsis. J Exp Bot 68:2333-2344

Mustafa G, Komatsu S (2016) Toxicity of heavy metals and metal-containing nanoparticles on plants. Biochim Biophys Acta 1864:932-494

Ohta M, Guo Y, Halfter U, Zhu JK (2003) A novel domain in the protein kinase SOS2 mediates interaction with the protein phosphatase2C ABI2. PNAS 100: $11771-11776$

Ozawa K (2009) Establishment of a high efficiency agrobacterium-mediated transformation system of rice (Oryza sativa L.). Plant Sci 176:522-527

Pan JW, Zheng K, Ye D, Yi HL, Jiang ZM, Jing CT, Pan WH, Zhu MY (2004) Aluminum-induced ultraweak luminescence changes and sister-chromatid exchanges in root tip cells of barley. Plant Sci 167:1391-1399

Pan W, Shou J, Zhou X, Zha X, Guo T, Zhu M, Pan J (2011) Al-induced cell wall hydroxyproline-rich glycoprotein accumulation is involved in alleviating $\mathrm{Al}$ toxicity in rice. Acta Physiol Plant 33:601-608

Pandey GK, Cheong YH, Kim BG, Grant JJ, Li L, Luan S (2007) CIPK9: a calcium sensor-interacting protein kinase required for low-potassium tolerance in Arabidopsis. Cell Res 17:411-421

Rudd JJ, Franklin-Tong VE (1999) Calcium signaling in plants. Cell Mol Life Sci 55: $214-232$

Sharma SS, Dietz KJ (2009) The relationship between metal toxicity and cellular redox imbalance. Trends Plant Sci 14:43-50

Shen JQ, Zheng ZZ, Pan WH, Pan JW (2014) Functions and action mechanisms of CBL-CIPK signaling system in plants. Plant Physiol J 50:641-650 (Chinese manuscript with English abstract)

Singh S, Parniske M (2012) Activation of calcium- and calmodulin-dependent protein kinase (CCaMK), the central regulator of plant root endosymbiosis. Curr Opin Plant Biol 15:444-453

Straub T, Ludewig U, Neuhauser B (2017) The kinase CIPK23 inhibits ammonium transport in Arabidopsis thaliana. Plant Cell 29:409-422

Sun T, Wang Y, Wang M, Li T, Zhou Y, Wang X, Wei S, He G, Yang G (2015) Identification and comprehensive analyses of the CBL and CIPK gene families in wheat (Triticum aestivum L.). BMC Plant Biol 15:269

Toki S, Hara N, Ono K, Onodera H, Tagiri A, Oka S, Tanaka H (2006) Early infection of scutellum tissue with agrobacterium allows high-speed transformation of rice. Plant J 47:969-976

de la Torre F, Gutierrez-Beltran E, Pareja-Jaime Y, Chakravarthy S, Martin GB, del Pozo O (2013) The tomato calcium sensor Cbl10 and its interacting protein kinase Cipk6 defense a signaling pathway in plant immunity. Plant Cell 25: 2748-2764

Wang JJ, Lu XK, Yin ZJ, Mu M, Zhao XJ, Wang DL, Wang S, Fan WL, Guo LX, Ye WW, Yu SX (2016a) Genome-wide identification and expression analysis of CIPK genes in diploid cottons. Genet Mol Res 15(4). https://doi.org/10.4238/ gmr15048852

Wang XP, Chen LM, Liu WX, Shen LK, Wang FL, Zhou Y, Zhang Z, Wu WH, Wang Y (2016b) AtKC1 and CIPK23 synergistically modulate AKT1-mediated lowpotassium stress responses in Arabidopsis. Plant Physiol 170:2264-2277
Weinl S, Kudla J (2009) The CBL-CIPK Ca ${ }^{2+}$-decoding signaling network: function and perspectives. New Phytol 184:517-528

Wong MH, Bradshaw AD (1982) A comparison of the toxicity of heavy metals using root elongation of rye grass lolium perenne. New Phytol 91:255-262

Xiong L, Yang Y (2003) Disease resistance and abiotic stress tolerance in rice are inversely modulated by an abscisic acid-inducible mitogen-activated protein kinase. Plant Cell 15:745-759

Xu J, Li HD, Chen LQ, Wang Y, Liu LL, He L, Wu WH (2006) A protein kinase, interacting with two calcineurin B-like proteins, regulates $\mathrm{K}+$ transporter AKT1 in Arabidopsis. Cell 125:1347-1360

Yan J, Niu F, Liu WZ, Zhang H, Wang B, Lan W, Che Y, Yang B, Luan S, Jiang YQ (2014) Arabidopsis CIPK14 positively regulates glucose response. Biochem Biophys Res Commun 450:1679-1683

Yu Q, An L, Li W (2014) The CBL-CIPK network mediates different signaling pathways in plants. Plant Cell Rep 33:203-214

Yu YH, Xia XL, Yin WL, Zhang HC (2007) Comparative genomic analysis of CIPK gene family in Arabidopsis and Populus. Plant Growth Regul 52:101-110

Zhang H, Feng XB, Larssen T, Qiu GL, Vogt RD (2010) In inland China, rice, rather than fish, is the major pathway for methylmercury exposure. Environ Health Perspect 118:1183-1188

Zhang H, Yang B, Liu WZ, Li H, Wang L, Wang B, Deng M, Liang W, Deyholos MK, Jiang YQ (2014) Identification and characterization of CBL and CIPK gene families in canola (Brassica napus L.). BMC Plant Biol 14:8

Zhang WH, Rengel Z (1999) Aluminum induces an increase in cytoplasmic calcium in intact wheat root tip cells. Aust J Plant Physiol 26:401-409

Zheng ZZ, Shen JQ, Pan WH, Pan JW (2013) Calcium sensors and their stress signaling pathways in plants. Yi Chuan 35:875-884 (Chinese manuscript with English abstract)

Zhu K, Chen F, Liu J, Chen X, Hewezi T, Cheng ZM (2016) Evolution of an intronpoor cluster of the CIPK gene family and expression in response to drought stress in soybean. Sci Rep 6:28225

\section{Submit your manuscript to a SpringerOpen ${ }^{\circ}$ journal and benefit from:}

- Convenient online submission

- Rigorous peer review

- Open access: articles freely available online

- High visibility within the field

- Retaining the copyright to your article

Submit your next manuscript at $\boldsymbol{\nabla}$ springeropen.com 